\title{
Earth's free oscillations recorded by free-fall OBS ocean-bottom seismometers at the Lesser Antilles subduction zone
}

\author{
A. Bécel, ${ }^{1,2}$ M. Laigle, ${ }^{1}$ J. Diaz, ${ }^{2}$ J.-P. Montagner, ${ }^{1}$ and A. Hirn ${ }^{1}$ \\ Received 2 September 2011; revised 2 November 2011; accepted 3 November 2011; published 20 December 2011.
}

[1] Three unburied ocean bottom seismometers (OBS) equipped with Trillium $240 \mathrm{~s}$ broad-band seismometers recorded spheroidal free oscillations of the Earth out to periods over $1000 \mathrm{~s}$ period, for the $\mathrm{M}=8.1$, April 1, 2007 Solomon Islands earthquake. In contrast to broadband observatories of the global network that operate in quiet continental locations, these instruments were dropped on the several-km thick layer of sediments of the forearc and accretionary wedge of the Lesser Antilles subduction zone. Furthermore, a high ambient noise level due to the ocean surface infragravity waves is expected to cover the frequency band of Earth's normal modes band when recorded at these sites. In spite of these hostile environmental conditions, the frequency of clearly defined peaks of the Earth's normal modes were measured after the earthquake. This suggests that the recording of normal modes and long period waves can be extended to parts of the hitherto inaccessible ocean with currently available OBS technology. Citation: Bécel, A., M. Laigle, J. Diaz, J.-P. Montagner, and A. Hirn (2011), Earth's free oscillations recorded by free-fall OBS ocean-bottom seismometers at the Lesser Antilles subduction zone, Geophys. Res. Lett., 38, L24305, doi:10.1029/2011GL049533.

\section{Introduction}

[2] In the framework of research programmes on the Lesser Antilles subduction zone funded by the European Union and the French and German governments [Hirn et al., 2010], about 80 ocean-bottom seismometers (OBS) from diverse European pools in Europe (INSU/IPGP (Paris), Geoazur (Nice), IfM-GEOMAR (Kiel) and AWI (Bremerhaven)) were deployed for several months in early 2007 (Figure 1). Among them was a number of wideband to broad-band seismometers and hydrophones. The OBS were located at nodes of a $150 \mathrm{~km} \mathrm{E-W}$ by $300 \mathrm{~km} \mathrm{~N}-\mathrm{S}$ grid of multichannel seismic reflection profiles. The OBS recorded arrivals from airgun shots for refraction seismics and travel time tomography, and monitored local and worldwide earthquake activity.

[3] Beyond the active seismic study, one of the aims of the project was also to assess whether seafloor instruments could record transient subduction zone signals such as NVT (nonvolcanic tremor) [Obara, 2002] and LFE (low-frequency events) [e.g., Ide et al., 2008]. The episodic occurrence of such seismic signals was originally discovered by land seismometers at the Cascadia [Rogers and Dragert, 2003] and Nankai-Tokai [Obara, 2002] subduction zones. Together

\footnotetext{
${ }^{1}$ Seismology, Institut de Physique du Globe de Paris, UMR 7514 CNRS, Paris, France.

${ }^{2}$ Institute of Earth Sciences 'Jaume Almera,' CSIC, Barcelona, Spain.

Copyright 2011 by the American Geophysical Union. 0094-8276/11/2011GL049533
}

with geodetically observed slip transients [Dragert et al., 2001; Rogers and Dragert, 2003], these signals may be heralds of megathrust subduction earthquakes [e.g., Hirn and Laigle, 2004]. These events were discovered in regions where the fore-arc region above the activated domain of the subduction interface is subaerial, allowing accurate estimation of the source locations using land stations. However, in most cases the forearc is under water, so seafloor stations are necessary to accurately detect and locate these signals. The Lesser Antilles subduction zone is a particularly challenging zone to monitor, because the basement lies beneath $5000 \mathrm{~m}$ of unconsolidated sediments, which itself can lie beneath $5000 \mathrm{~m}$ of water.

[4] Our dataset consisting of several months of continuous recordings from a set of diverse OBS provides information on the feasibility of seafloor seismological measurements, and on the effect of site noise, instrument type and environmental conditions, on the data quality. We report here the unexpected high quality of the recorded seismological signal over a very broad frequency band using free-fall OBS. We compare the data quality with that observed at the nearby FDF broad-band observatory of the GSN-GEOSCOPE global network. In particular, normal modes of vibration of the Earth down to the gravest modes $(\sim 1 \mathrm{mHz})$ were recorded on several OBS after the $\mathrm{Mw}=8.1$ Solomon Islands earthquake of April 1, 2007. This study is well aligned with other efforts attempting to explore normal mode signals from a variety of instruments, such as from gravimeters [e.g., Widmer-Schnidrig, 2003], extensometers [e.g., Park et al., 2008] and tiltmeters [e.g., Ferreira et al., 2006].

\section{Earth's Response to Earthquakes}

[5] As a finite body, the Earth can resonate as a whole at discrete low frequencies. These modes of vibration, which were theoretically predicted before being observed, are named free oscillations. The largest 20th century earthquake, the magnitude 9.5 Chile event in 1960, provided the first reliable observations of the Earth's free oscillations down to the gravest spheroidal normal mode ${ }_{0} \mathbf{S}_{\mathbf{2}}$ at $3232 \mathrm{~s}$ period (0.309 mHz) [Alsop et al., 1961; Benioff et al., 1961; Ness et al., 1961; Bolt and Marussi, 1962; Connes et al., 1962]. At the time such observations could only be obtained at very few sites worldwide where instruments had reached a suitable quality. The study of Earth's free oscillation and its associated normal mode theory play a central role in seismology, since normal modes contain fundamental information about the large-scale deep structure down to the solid anisotropic inner core and on the magnitude and moment tensor of great earthquakes such as the largest $21 \mathrm{st}$ century earthquake yet observed, the Sumatra-Andaman event (26 dec. 2004; $\mathrm{Mw}=9.3$ ) [Park et al., 2005]. The free oscillations excited by this event were detected at hundreds 


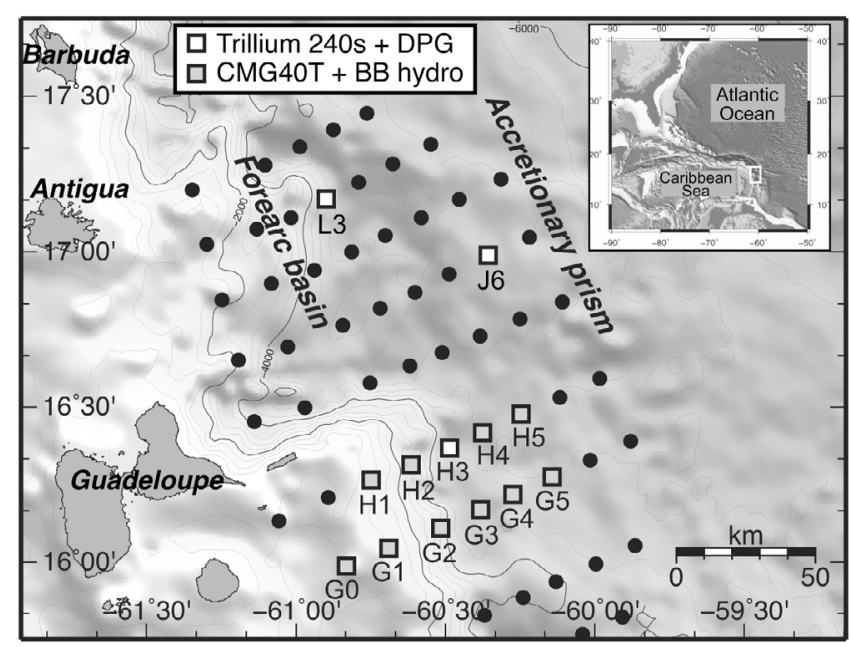

Figure 1. Map of offshore Lesser Antilles arc with OBS deployed. White squares represent the INSU/IPGP BB-OBS of Scripps type with Trillium $240 \mathrm{~s}$ seismometers discussed in text. Grey squares are the BB-hydrophone HTI. Inset shows the OBS network location in the Western Atlantic Ocean.

of stations. The exceptional strength of this earthquake provided an adequate signal to noise over time series reaching 30 days to directly observe the mode splitting related to the rotation, ellipticity and lateral internal heterogeneities of the Earth [e.g., Okal and Stein, 2009; Roult et al., 2010].

[6] Free oscillations are now routinely observed for the largest earthquakes $(\mathrm{M}>8)$ at seismic stations equipped with high-quality broadband digital seismometers. Background free oscillations, referred to as the seismic "hum" are incessantly excited by the non-linear interactions between the solid and fluid (ocean and atmosphere) Earth [Tanimoto et al., 1998; Suda et al., 1998; Kobayashi and Nishida, 1998; Webb, 2007; Rhie and Romanowicz, 2004]. However, the spatial sampling of the displacement field is still limited to the smaller part of the Earth corresponding to the continents and a few isolated islands. Laske et al. [2009] reported that at least five of the OBS of the 2005 PLUME project centered on Hawaii, have recorded the spheroidal normal mode ${ }_{0} \mathbf{S}_{\mathbf{8}}$ with periods as long as $708 \mathrm{~s}(1.413 \mathrm{mHz})$, for the $M=8.6$ Simelue-Nias earthquake of 28 March 2005, the third largest earthquake since the 1960 Chile event. This observation provides the first instance of recovering ultra-low-frequency normal modes on unburied ocean-bottom seismometers. For comparison, the nearby GSN-GEOSCOPE station KIP on Hawaii recorded modes out to twice the period of ${ }_{0} \mathbf{S}_{8}$ : namely mode, ${ }_{0} \mathbf{S}_{4}$ at $1546 \mathrm{~s}$, $0.647 \mathrm{mHz}$ with its STS-1 broad-band seismometer.

\section{Data}

[7] The results presented here are based on the analysis of the longest period seismometers in our experiment: which are 3 broadband OBS designed by Scripps Institution of Oceanography and owned and operated by the INSU/ IPGP pool. These BB-OBS are equipped with Trillium T240 seismometers, with a flat velocity response down to 240 seconds and a long-period differential pressure gauge (DPG) [Cox et al., 1984]. In the northern half of the survey, 10 wide-band OBS using Güralp CMG40 seismometers, with a flat velocity response out to $60 \mathrm{~s}$ and a broadband hydrophone were also considered. All OBS were free-fall deployed on the fore-arc sedimentary basin, 50 to $100 \mathrm{~km}$ from the primary volcanic arc (Figure 1). The 3 BB-OBS (sites $\mathrm{H} 3, \mathrm{~J} 6$ and $\mathrm{L} 3$ ), are located $50 \mathrm{~km}$ from one another at 4600 to $5100 \mathrm{~m}$ water depth. They were deployed on the sediments of the accretionary wedge above the subducting plate or on the thick fore-arc sedimentary basins above the backstop plate. We also will show data from the land-based FDF seismometer, which is in an underground vault within an extinct volcanic peak on the sheltered leeward side of Martinique island $(20 \mathrm{~km}$ from the windward eastern coast).

\section{Quality Control With Earth Tides, and Infragravity Noise Signal}

[8] In the 1960s, cabled ocean-bottom seismometers offshore California and Bermuda provided first recordings of long period seismic signals and their sensitivity to tidal periods [Sutton et al., 1965; Latham and Sutton, 1966; Barstow et al., 1989]. Such signals are also reported by Montagner et al. [1994] from a temporary deployment of seismometers outside and inside a sea-bottom borehole in the deep ocean.
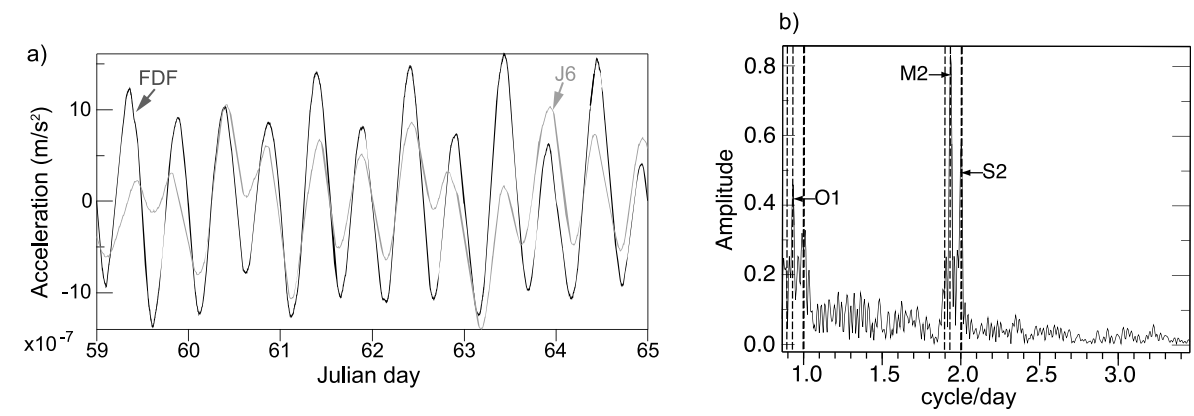

Figure 2. (a) Vertical component acceleration from the Trillium-240 of BB-OBS at J6 compared with nearby STS-2Z at GEOSCOPE observatory FDF, showing similar quasi diurnal and semi-diurnal periods of the solid Earth and oceanic load tides. Instrument response has been removed; the waveforms have been low pass filtered. (b) Acceleration vertical amplitude spectrum at BB-OBS J6 over 52 days, showing main tidal components in cycles/day. Significant spectral peaks corresponding to the O1 (diurnal) and M2, S2 (semidiurnal) tidal component are picked. Dashed vertical black lines correspond to the theoretical values of the tidal components. 


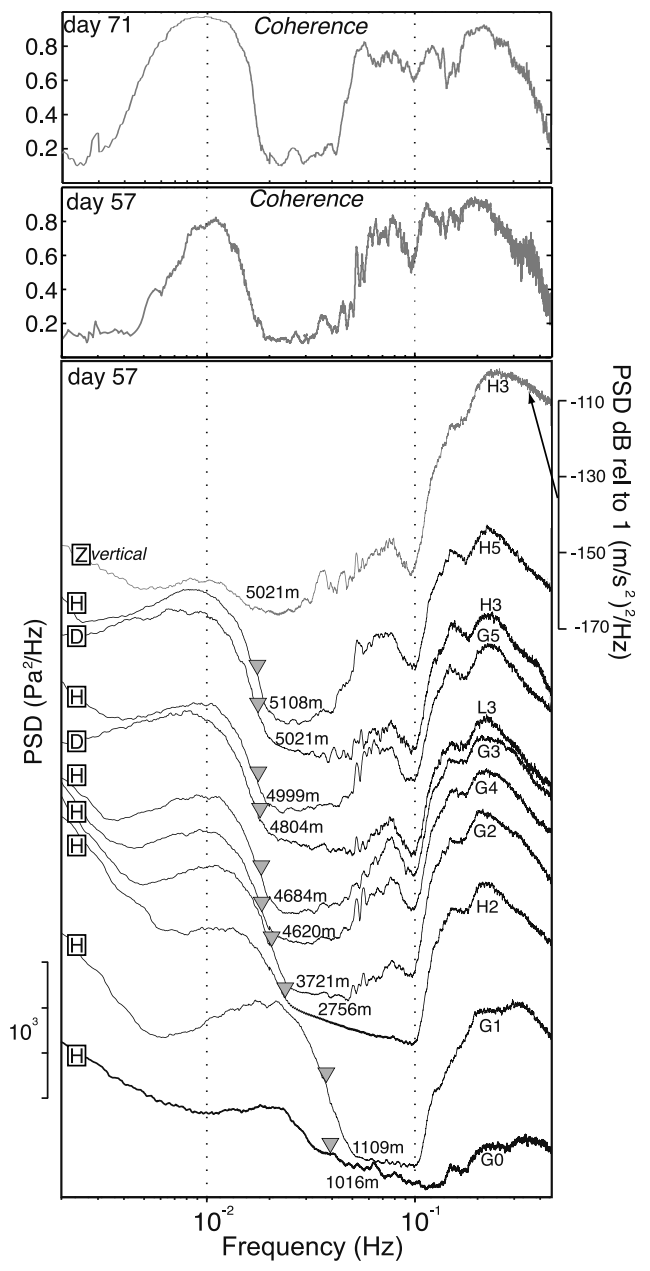

Figure 3. (top and middle) Coherence computed between the acceleration vertical component and the DPG for station H3 for days JD 71 and 57 with respectively a strong and a low level of low frequency infragravity waves. At higher frequency high coherence is for the microseismic noise. (bottom) Spectra. Upper trace is vertical seismometer component (labeled Z), others of DPG, differential pressure gauges (D) or low-frequency hydrophones $(\mathrm{H})$ labeled with OBS site and water depth. PSD estimates have been calculated using one-day files (Julian Day 57). Triangles on traces indicate infragravity wave high-frequency cut-off value to the low noise notch, computed with the dispersion relation of freely traveling surface gravity waves for OBS depth. The graduated bar on the left side gives the scale of the logarithmic amplitude variation of each of the curves that have been shifted manually from one another for clarity.

[9] In our experiment, the quasi diurnal and quasi semidiurnal solar and lunar components of solid Earth and oceanic load tides are clearly detected at the sea-bottom at site J6 which is equipped with a Trillium $240 \mathrm{~s}$ broadband seismometer (Figure 2). For the two other BB-OBS seismometers the comparison of the tidal period signals succeeds only piecewise, possibly due to site instabilities every few days. The signal compares well in phase and in amplitude with the corresponding record of the nearby GEOSCOPE land station FDF equipped with the standard broadband STS-2 seismometer. The slight difference between the tidal amplitudes recorded at the OBS site and at site FDF could be due to the ocean tide loading effects as well as the changing gravitational attraction of the water height varying over the sites. This recording of tides with free-fall OBS demonstrates the data quality down to ultra-low frequencies, since detection of the tidal signal on a broadband seismometer is taken as indicating a high quality station site and instrument.

[10] The Trillium T240s seismometers used in the 3 BBOBS use a Galperin [1955] configuration, in which the vertical and horizontal components of ground motion are retrieved from the output signals of three physically identical sensors with inclined sensitive axes and mounted at 120 degree angles. This is different from seismometer setups in cardinal directions that have mechanically different vertical and horizontal sensors such as in the case of the CMG40T OBS. This latter instrument has a vertical inverted pendulum which is a different design than the horizontal garden gate type pendula. Components with cardinal orientation are then differently sensitive to gravity and its tidal variation, to noise, and to crosstalk between their outputs in dependence of their leveling adjustment [e.g., Pillet et al., 2009].

[11] As shown on a one-day spectrum (Figure 3), there is a domain of high amplitudes at low frequencies, in addition to the higher frequency bands of the microseismic noise. The high signal coherence computed between the vertical ground motion component of a BB-OBS and the pressure signal (Figure 3, top), that defines the material compliance under the OBS [e.g., Crawford et al., 1991], qualifies the corresponding noise at periods longer than several tens of seconds to be the signal of infragravity waves due to ocean surface waves. The low-frequency hydrophones of 10 other instruments resolve similarly such notable amplitude at long periods. The whole set of observations allows then to verify that the notch frequency of the infragravity noise at sites from $5000 \mathrm{~m}$ to $1000 \mathrm{~m}$ water depth (Figure 3 ) changes from 20 to $40 \mathrm{mHz}$ (50 to $25 \mathrm{~s}$ period) corresponding to the theoretical hydrodynamic filtering [e.g., Webb et al., 1991; Araki et al., 2004]. This had been observed in a previous simultaneous deployment of 3 OBS at different depths in the Faeroes basin [Crawford and Singh, 2008]. The coherence, and amplitude level of these infragravity noise change with time (Figure 3, top and middle; also Figure S1 in Text S1). ${ }^{1}$

\section{Recording of the Normal Modes Down to Very Low Frequencies}

[12] The recording during the 2005 PLUME project of the large $\mathrm{M}=8.6$ Simelue-Nias earthquake has provided the first sea-floor observations of ultra-low-frequency normal modes on unburied ocean-bottom seismometers down to the mode ${ }_{0} \mathbf{S}_{\mathbf{8}}$ [Laske et al., 2007, 2009].

[13] We present here observations from the much weaker magnitude $\mathrm{M}=8.1$, April 1, 2007 Salomon Islands event. Events of such magnitude occur at least once a year. Data records have been processed in order to investigate whether spectral peaks of the Earth's normal modes are observable in response to this smaller excitation. Spectral analysis has been applied to the sea-bottom vertical motion data from the BB seismometer for different time durations after the earthquake origin time, from a few to thirty days. As a compromise

${ }^{1}$ Auxiliary materials are available in the HTML. doi:10.1029/ 2011 GL049533. 


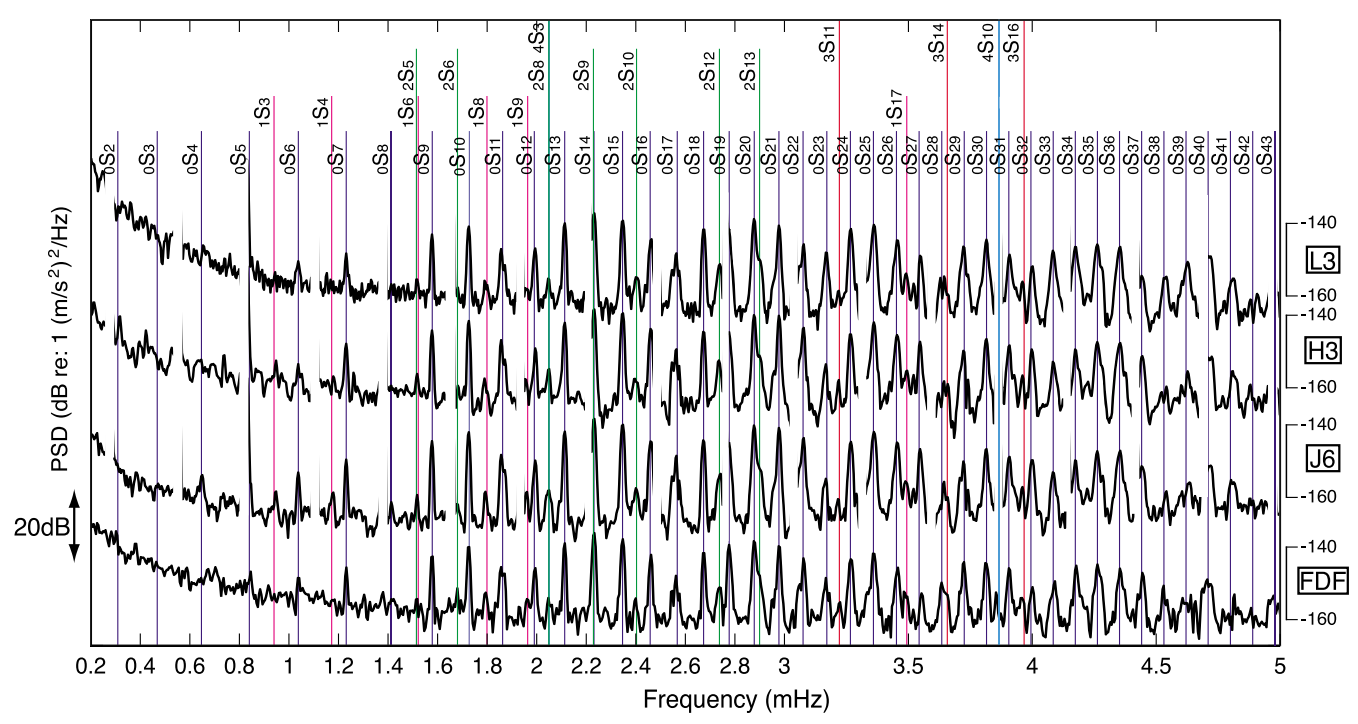

Figure 4. Vertical Power Spectral Density (PSD) for the 3 broadband Trillium $240 \mathrm{~s}$ OBS and STS-2 seismometer at FDF on land. The linear trend and the mean have been removed from the data. A band pass filter between 0.0001 to $0.01 \mathrm{~Hz}$ has been applied before removing the sensor pole-zero response and before converting the signal to acceleration. Power spectral density functions have been estimated using Welch averaging with 50\% overlap and Hamming tapered windows. The PSD have been estimated using 8-days long signal after the magnitude 8.1 Solomon Island earthquake. Colored Vertical lines indicate the spheroidal frequencies from the anisotropic PREM model [Dziewonski and Anderson, 1981]. Spurious peaks with harmonics at $3621 \mathrm{~s}$ and overtones are present in both the time series and in the frequency spectrum. Hence the spikes in the spectrum can be unambiguously identified and they have been erased from the spectra. Vertical scales in $\mathrm{dB}$ $(-160 \mathrm{~dB} /-140 \mathrm{~dB})$ for each PSD estimates have been added.

between the strength of amplitudes that decreases and the resolution in frequency that increased with the length of time series processed, the spectra for 8 days are displayed in Figure 4 . This is quite a short time span with respect to the 30 days that could be used in the case of the magnitude 9 Andaman Sumatra major earthquake of December 26, 2004 [Okal and Stein, 2009; Roult et al., 2010].

[14] The spectra from the vertical component of the Trillium 240 s seismometers of the 3 Scripps type OBS of INSU/IPGP in Figure 4 display the series of discrete peaks of the Earth's spheroidal normal modes of vibration in response to the earthquake excitation, from 0.2 to $5 \mathrm{mHz}, 5000 \mathrm{~s}$ to $200 \mathrm{~s}$. The 3 BB-OBS and the FDF spectra are consistent. In the present case the OBS recordings are comparable with those obtained at site FDF in Martinique with the STS2 broadband seismometer. In the case of Hawaii and of the much larger earthquake reported by Laske et al. [2009], the OBS did not record modes with period as long as those recorded at the nearby island observatory KIP.

[15] Spheroidal modes are very clear throughout the range. Mode ${ }_{0} \mathbf{S}_{\mathbf{6}}$, just above $1 \mathrm{mHz}$ or below 1000 s period is the gravest mode clearly recorded by all three OBS and FDF, most clearly by OBS J6 on the accretionary wedge. This OBS also provides a unique clear record of ${ }_{0} \mathbf{S}_{4}$ at $1546 \mathrm{~s}$, $0.647 \mathrm{mHz}$, an even lower frequency mode, mainly related to mantle structure. At about the frequency of $0.3 \mathrm{mHz}$ expected for the gravest mode ${ }_{0} \mathbf{S}_{2}$, there appears a small but distinct peak on H3. This is however not consistently stable for all different time window lengths analyzed and thus we cannot strongly claim to have recorded the very gravest of modes.

[16] Several harmonic modes are also resolved in-between fundamental ones, such as modes which are sensitive to mantle and outer core: ${ }_{1} \mathbf{S}_{\mathbf{3}}$ and ${ }_{\mathbf{3}} \mathbf{S}_{\mathbf{1}}$ at $0.9439 \mathrm{mHz}, 1059 \mathrm{~s}$, between normal modes ${ }_{0} \mathbf{S}_{5}$ and ${ }_{0} \mathbf{S}_{6},{ }_{1} \mathbf{S}_{\mathbf{4}}$ between modes ${ }_{0} \mathbf{S}_{6}$ and ${ }_{0} \mathbf{S}_{7},{ }_{2} \mathbf{S}_{\mathbf{5}}-{ }_{1} \mathbf{S}_{\mathbf{6}}$, between modes ${ }_{0} \mathrm{~S}_{8}$ and ${ }_{0} \mathrm{~S}_{9}$, and further ones at higher frequencies.

\section{Discussion}

[17] This is the first example of recording the Earth's normal modes to very long period in what was expected to be very poor site conditions of a soft sea-bottom underlain by kilometers thick recent sediments and recorded during a winter-spring season of high level of ocean surface infragravity waves in the North Atlantic ocean. Furthermore this observation is obtained from an earthquake that is not exceptionally large, since events of that class of magnitude occur at least once a year on average. The normal mode spectral peaks are found to stick out from noise by $20-30 \mathrm{~dB}$. Moreover, the amplitude of the infragravity waves decreases with increasing water depth (Figure 3). Hence, normal modes of the Earth will be better seen on OBS records in deep water [Araki et al., 2004; Crawford et al., 1991]. This may hold for similar conditions in other mid-latitudes oceans, although in the Pacific ocean the infragravity noise is typically $20-30 \mathrm{~dB}$ above that of the Atlantic ocean [Webb et al., 1991]. None the less normal modes with slightly shorter periods, but from a larger earthquake, have been recorded in the Pacific Ocean near Hawaii [Laske et al., 2009].

[18] These findings show it is possible to consider extending the recording of normal modes to parts of the hitherto inaccessible largest area of the Earth's surface that is covered by oceans. This may open the way for sampling part of these larger areas for the response of lateral heterogeneity in deep structure, beyond the present reduced spatial sampling of the Earth from its continents and islands only. 
[19] The original goal of the experiment was to test for the conditions of observation at sea-bottom of long period signals such as have been found above some subduction zones with land seismometers and interpreted of endogeneous origin. At these sites on a submerged forearc with thick sedimentary cover, the quality of OBS records is unexpected and comparable to the records of a seismological observatory on land nearby at very long tidal periods, and also in the 1000 to $100 \mathrm{~s}$ range, as shown by the recording of the Earth's normal modes at these long periods.

[20] Acknowledgments. This research has been supported by the European Union FP6 NEST (New and emerging Science and Technology)INSIGHT programme, under project "THALES WAS RIGHT" 029080, by French National Research Agency (ANR) CATTELL programme under project SUBSISMANTI and by the OBSISMER programme including French National, Martinique Regional, and EU FEDER funding. The FDF GEOSCOPE station is one of the GDSN broad-band observatories maintained by GEOSCOPE and the Volcanological Observatory of Mt Pelée, Martinique, of IPG Paris. Additional funding was provided by Spanish research project SESUBA CGL2005-25076-E/BTE. We acknowledge the help of Wayne Crawford and Spahr Webb in revising the manuscript and the constructive reviews of Rudolf Widmer-Schnidrig and an anonymous referee. We thank the Thales scientific party and more specifically the P.I. of the project: A. Hirn, E. Flueh, P. Charvis, J. Gallart, M. Sachpazi, E. Kissling, and R. Nicolich. This is IPGP contribution 3246.

[21] The Editor thanks the two anonymous reviewers.

\section{References}

Alsop, L. E., G. H. Sutton, and M. Ewing (1961), Free oscillations of the Earth observed on strain and pendulum seismographs, J. Geophys. Res., 66, 631-641, doi:10.1029/JZ066i002p00631.

Araki, E., M. Shinohara, S. Sacks, A. Linde, T. Kanazawa, H. Shiobara, H. Mikada, and K. Suyehiro (2004), Improvement of seismic observation in the ocean by use of seafloor boreholes, Bull. Seismol. Soc. Am., 94, 678-690, doi:10.1785/0120020088.

Barstow, N., G. H. Sutton, and J. A. Carter (1989), Particle motion and pressure relationships of ocean bottom noise: $3900 \mathrm{~m}$ depth; 0.003 to $5 \mathrm{~Hz}$, Geophys. Res. Lett., 16, 1185-1188, doi:10.1029/GL016i010p01185.

Benioff, H. V., F. Press, and S. W. Smith (1961), Excitation of free oscillations of the Earth by earthquakes, J. Geophys. Res., 66, 605-619, doi:10.1029/JZ066i002p00605.

Bolt, B. A., and A. Marussi (1962), Eigenvibrations of the Earth observed at Trieste, Geophys. J. R. Astron. Soc., 6, 299-311, doi:10.1111/j.1365246X.1962.tb00353.x.

Connes, J., P. A. Blum, G. Jobert, and N. Jobert (1962), Observation des oscillations propres de la Terre, Ann. Geophys., 18, 260-268.

Cox, C. S., T. Deaton, and S. C. Webb (1984), A deep sea differential pressure gauge, J. Atmos. Oceanic Technol., 1(3), 237-246, doi:10.1175/ 1520-0426(1984)001<0237:ADSDPG $>2.0$.CO;2.

Crawford, W. C., and S. C. Singh (2008), Sediment shear properties from seafloor compliance measurements: Faroes-Shetland basin case study, Geophys. Prospect., 56, 313-325, doi:10.1111/j.1365-2478.2007.00672.x.

Crawford, W. C., S. C. Webb, and J. A. Hildebrand (1991), Seafloor compliance observed by long-period pressure and displacement measurements, J. Geophys. Res., 96, 16,151-16,160, doi:10.1029/91JB01577.

Dragert, H., K. Wang, and T. S. James (2001), A silent slip event on the Deeper Cascadia, Science, 292, 1525-1528, doi:10.1126/science.1060152.

Dziewonski, A. M., and D. L. Anderson (1981), Preliminary reference Earth model, Phys. Earth Planet. Inter., 25, 297-356, doi:10.1016/ 0031-9201(81)90046-7.

Ferreira, A. M. G., N. F. d'Oreye, J. H. Woodhouse, and W. Zurn (2006), Comparison of fluid tiltmeter data with long-period seismograms: Surface waves and Earth's free oscillations, J. Geophys. Res., 111, B11307, doi:10.1029/2006JB004311.

Galperin, E. I. (1955), Azimuthal Method of Seismic Observations [in Russian]. Gostoptechizdat, Moscow.

Hirn, A., and M. Laigle (2004), Silent heralds of megathrust earthquakes, Science, 305, 1917-1918, doi:10.1126/science.1101152.

Hirn, A., M. Laigle, P. Charvis, E. Flueh, J. Gallart, E. Kissling, J. F. Lebrun, R. Nicolich, and M. Sachpazi (2010), An integrated approach to the seismic activity and structure of the central Lesser Antilles subduction megathrust seismogenic zone, Geophys. Res. Abstr., 12, EGU2010-11248.

Ide, S., K. Imanishi, Y. Yoshida, G. C. Beroza, and D. R. Shelly (2008), Bridging the gap between seismically and geodetically detected slow earthquakes, Geophys. Res. Lett., 35, L10305, doi:10.1029/2008GL034014.

Kobayashi, N., and K. Nishida (1998), Continuous excitation of planetary free oscillations by atmospheric disturbances, Nature, 395(6700), 357-360, doi:10.1038/26427.

Laske, G., J. A. Orcutt, J. A. Collins, R. S. Detrick, C. J. Wolfe, S. C. Solomon, D. A. Bercovici, and E. H. Hauri (2007), Broadband ocean bottom instruments record Earth's free oscillations during the Hawaiian PLUME experiment, Eos Trans. AGU, 88(52), Fall Meet. Suppl., Abstract S23A-1107.

Laske, G., J. A. Collins, C. J. Wolfe, S. C. Solomon, R. S. Detrick, J. A. Orcutt, D. Bercovici, and E. H. Hauri (2009), Probing the Hawaiian hot spot with new Broadband Ocean Bottom instruments, Eos Trans. AGU, 90(41), 362-363, doi:10.1029/2009EO410002.

Latham, G. V., and G. H. Sutton (1966), Seismic measurements on the ocean floor: 1. Bermuda area, J. Geophys. Res., 71, 2545-2573.

Montagner, J. P., et al. (1994), The French pilot experiment OFMSISMOBS: First scientific results on noise level and event detection, Phys. Earth Planet. Inter., 84, 321-336, doi:10.1016/0031-9201(94) 90050-7.

Ness, N. F., J. C. Harrison, and L. B. Slichter (1961), Observations of free oscillations of the Earth, J. Geophys. Res., 66, 621-629, doi:10.1029/ JZ066i002p00621.

Obara, K. (2002), Nonvolcanic deep tremor associated with subduction in southwest Japan, Science, 296, 1679-1681, doi:10.1126/science.1070378.

Okal, E. A., and S. Stein (2009), Observations of ultra long period normal modes from the 2004 Sumatra-Andaman earthquake, Phys. Earth Planet. Inter., 175, 53-62, doi:10.1016/j.pepi.2009.03.002.

Park, J., et al. (2005), Earth's free oscillations excited by the 26 December 2004 Sumatra-Andaman earthquake, Science, 308, 1139-1144, doi:10.1126/ science. 1112305 .

Park, J., A. Amoruso, L. Crescentini, and E. Boschi (2008), Long-period toroidal Earth free oscillations from the great Sumatra-Andaman earthquake observed by paired laser extensometers in Gran Sasso, Italy, Geophys. J. Int., 173, 887-905, doi:10.1111/j.1365-246X.2008.03769.x.

Pillet, A., A. Deschamps, D. Legrand, J. Virieux, N. Béthoux, and B. Yates (2009), Interpretation of broadband Ocean-Bottom Seismometer horizontal data seismic background noise, Bull. Seismol. Soc. Am., 99, 1333-1342, doi: $10.1785 / 0120080123$.

Rhie, J., and B. Romanowicz (2004), Excitation of Earth's continuous free oscillations by atmosphere-ocean-seafloor coupling, Nature, 431, 552-556, doi:10.1038/nature02942.

Rogers, G., and H. Dragert (2003), Episodic tremor and slip on the Cascadia subduction zone: The chatter of silent slip, Science, 300, 1942-1943, doi:10.1126/science.1084783.

Roult, G., J. Roch, and E. Clévédé (2010), Observation of split modes from the $26^{\text {th }}$ December 2004 Sumatra-Andaman mega-event, Phys. Earth Planet. Inter., 179, 45-59, doi:10.1016/j.pepi.2010.01.001

Suda, N., K. Nawa, and Y. Fukao (1998), Earth's background free oscillations, Science, 279, 2089-2091, doi:10.1126/science.279.5359.2089.

Sutton, G. H., W. McDonald, D. Prentiss, and S. N. Thanos (1965), Oceanbottom seismic observatories, Proc. IEEE, 53, 1909-1921, doi:10.1109/ PROC.1965.4468.

Tanimoto, T., J. Um, K. Nishida, and N. Kobayashi (1998), Earth's continuous oscillations observed on seismically quiet days, Geophys. Res. Lett., 25, 1553-1556, doi:10.1029/98GL01223.

Webb, S. C. (2007), The Earth's 'hum' is driven by ocean waves over the continental shelves, Nature, 445, 754-756, doi:10.1038/nature05536.

Webb, S. C., X. Zhang, and W. Crawford (1991), Infragravity waves in the deep ocean, J. Geophys. Res., 96(C2), 2723-2736, doi:10.1029/90JC02212.

Widmer-Schnidrig, R. (2003), What can superconducting gravimeters contribute to normal-mode seismology?, Bull. Seismol. Soc. Am., 93(3), 1370-1380, doi: $10.1785 / 0120020149$.

A. Bécel, A. Hirn, M. Laigle, and J.-P. Montagner, Seismology, Institut de Physique du Globe de Paris, UMR 7514 CNRS, 1, place Jussieu, F-75238 Paris CEDEX 05, France. (becel@ipgp.fr; laigle@ipgp.fr; jpm@ipgp.fr; hirn@ipgp.fr)

J. Diaz, Institute of Earth Sciences 'Jaume Almera,' CSIC, c/ Solé i Sabarís s/n, E-08028 Barcelona, Spain. (jdiaz@ija.csic.es) 